\title{
Low-frequency variability in the Southern Ocean region in a simplified coupled model
}

\author{
Guillaume Maze, ${ }^{1,2}$ Fabio D'Andrea, ${ }^{2}$ and Alain Colin de Verdière ${ }^{1}$ \\ Received 21 July 2006; revised 13 January 2005; accepted 6 February 2006; published 16 May 2006.
}

[1] Patterns of interannual variability of the ocean-atmosphere coupled system in the Southern Hemisphere extratropics are studied with a simple dynamical model in order to determine the basic physical processes of interaction independently of tropical forcing. The model used is an atmospheric quasi-geostrophic model coupled to a "slab" oceanic mixed layer, which includes mean geostrophic advection by the Antarctic Circumpolar Current (ACC). The ocean-atmosphere coupling occurs through surface heat fluxes and Ekman current heat advection. In a fully coupled simulation, the atmospheric part of the model, which includes high-frequency transient eddies at midlatitudes, exhibits a strong Southern Annular Mode (SAM) as the first mode of variability at interannual timescales. The SAM-related wind anomalies induce Ekman currents in the mixed layer which produce sea surface temperature anomalies. These are then advected along by the ACC. A forced mechanism where the ocean role is reduced to advect the sea surface temperature (SST) appears sufficient to reproduce the main features of the variability. Nevertheless, a positive feedback of the ocean was also found. It operates through anomalous Ekman currents heat advection and contributes to the maintenance of the SST anomaly.

Citation: Maze, G., F. D'Andrea, and A. Colin de Verdière (2006), Low-frequency variability in the Southern Ocean region in a simplified coupled model, J. Geophys. Res., 111, C05010, doi:10.1029/2005JC003181.

\section{Introduction}

[2] Climate variability of the Southern Ocean (SO) region has been comparatively less studied than the regions of the Northern Hemisphere. Since about twenty years, however, availability of new in situ and satellites observations, and the consequent improvement of reanalysis data sets, have triggered new interest. The SO has a peculiar geography: bounded to the south by the quasi-circular and pole-centered Antarctica continent, it is not interrupted by any meridional coast from mid to high latitudes. Consequently, it easily redistributes local climatic anomalies among all oceans. Identifying physical processes that drive this redistribution, as well as the origin of the anomalies is an important goal in the climate studies.

[3] Using reanalysis data from the European Centre for Medium-Range Weather Forecasts (ECMWF) and sea surface height from TOPEX/Poseidon satellite, White and Peterson [1996] (hereinafter referred to as WP96) and Jacobs and Mitchell [1996] have discovered oceanic and atmospheric anomalies propagating around Antarctica in 810 years. This phenomenon, called Antarctic Circumpolar Wave (ACW), has been initially described as a wave phenomenon with a zonal wave number two and a constant phase relationship between sea surface temperature (SST)

\footnotetext{
${ }^{1}$ Laboratoire de Physique des Océans, Brest, France,

${ }^{2}$ Laboratoire de Météorologie Dynamique, Paris, France.
}

Copyright 2006 by the American Geophysical Union. 0148-0227/06/2005JC003181\$09.00 and sea level pressure (SLP). The phase relation is similar to the one observed in the North Pacific at decadal periods [Nakamura et al., 1997] and in some North Atlantic patterns [Kushnir and Held, 1996] with high SLP located downstream (eastward) of warm SST. In the circular geometry of the SO, this gives SLP and SST in quadrature.

[4] The ACW has been studied with several analytical models focusing on planetary waves dynamics coupled to simple ocean models [Qiu and Jin, 1997; White et al., 1998; Goodman and Marshall, 1999; Talley, 1999; Baines and Cai, 2000; Colin de Verdière and Blanc, 2001]. All these models reproduce some of the ACW's characteristics as described by WP96. They possess different instability mechanisms which often differ also in the value of the growth rates. However, it was also found that an atmospheric stochastic forcing of the Southern Ocean is able to reproduce characteristics of ACW-like variability [Weisse et al., 1999; Haarsma et al., 2000; Verdy et al., 2006] emphasizing the necessity to include a more realistic atmospheric turbulence.

[5] The ACW has also been studied in oceanic and/or atmospheric global circulation models [Christoph et al., 1998; Motoi et al., 1998; Weisse et al., 1999; Cai et al., 1999; Bonekamp et al., 1999]. These models allow for a full representation of the climate system physics and long simulations can provide more significant statistics, which is not the case for short observational data sets. Differences with observations are significant. General circulation models (GCMs) exhibit a zonal wave number three standing wave in the atmosphere and an eastward propagating wave 


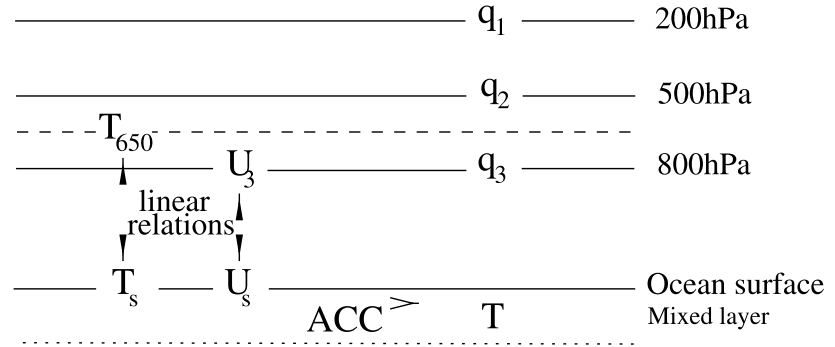

Figure 1. Schematic of vertical discretization of the ocean-atmosphere model.

(sometimes quasi-standing) with zonal wave number two or three in the ocean. These results produced a debate concerning the ACW and its very existence [Christoph et al., 1998; Cai et al., 1999]. Additionally, other studies have shown that climatic anomalies in the ACW could be initiated through teleconnections from El Niño-Southern Oscillation (ENSO) [Peterson and White, 1998; Cai and Baines, 2001] and even interact with it [White and Cayan, 2000; White et al., 2002; White and Annis, 2004]. The difficulty of numerical models to reproduce ENSO-induced variabilities in mid-to-high latitudes can be at the origin of the differences from observations [Cai and Baines, 2001].

[6] The disagreement between observations and numerical simulations have been moderated in studies using longer data sets, that have completed the ACW description. It seems that SLP, and other atmospheric variables, are not always propagating and can take the shape of a zonal wave number three standing wave pattern [Bonekamp et al., 1999; Carril and Navarra, 2001; Venegas, 2003; Park et al., 2004]. The ACW could be the combination of two signals having different origins and mechanisms [Venegas, 2003]. The first, eastward propagative and of zonal wave number two, may be the result of an extratropical dynamical mechanism but with ENSO as a tropical trigger. This is the dominant signal for the time period 1985-1994 analyzed by WP96. The second, standing in the atmosphere and perhaps propagative in the ocean, of zonal wave number three, is restricted to mid-to-high latitudes and may have dynamics related to the Southern Annular Mode (SAM) [Thompson and Wallace, 2000].

[7] The goal of this paper is to study the SO variability independently of remote forcing from low latitudes, focusing on intrinsic midlatitudes dynamics. We use a model of intermediate complexity, in between full blown climate models and the long wave analytical models reviewed above. It is an atmospheric quasi-geostrophic tridimensional model coupled to a "slab" oceanic mixed layer of constant depth, which includes mean geostrophic advection by the ACC. The atmospheric part has a good representation of atmospheric transient dynamics, including baroclinic eddies and their generation processes.

[8] This paper studies the interannual variability in the Southern Ocean, represented by the sea surface temperature. Our goals are first to describe this variability, second to identify how SST anomalies are created, and last to determine how important is the coupling between each climatic components and how they interact with each other. To do so, the model is integrated in three different configurations.
First, ocean and atmosphere are fully coupled (CPL) and can interact with each other (CPL run). Second, the ocean is passively forced by the atmosphere which in turn only feel climatological boundary conditions at the ocean surface. This configuration, called hereafter FR-OC, turns off ocean feedback on the atmosphere and simply allows to find out if the atmospheric forcing is sufficient to reproduce SO variability. Third, the atmosphere is passively forced by the ocean, i.e., the mean "equilibrium" atmospheric response to SST anomaly is studied. This configuration, called hereafter FR-AT, identifies how the atmospheric feedback on the SO explains the differences between CPL and FR-OC simulations.

[9] Numerical simulations CPL and FR-OC consist of 1100 years long perpetual winter integrations. The first 100 years are used to spin-up the ocean and the atmosphere to their equilibrium regime. We recorded monthly means of each variable of the following 1000 years, and then computed monthly anomalies from the long-term mean state. We also used daily atmospheric stream function fields from the last 100 years of integrations in order to compute storm track statistics of the atmosphere (a 11 days square window was used). Numerical simulation FR-AT consists of two 50 years long integrations. The first one is a control integration, performed with a climatological SST field and the second one is an anomalous integration where a SST anomaly is added to the climatological SST. The stationary atmospheric response to the SST anomaly is defined as the 50 -year long-term mean difference between the anomalous and the control integration.

[10] Section 2 describes the model's equations (section 2.1) and the climatology of the CPL simulation (section 2.2). Section 3 describes the interannual variability of the CPL simulation, first focusing on the SST and next extending the description to atmospheric covariabilities. Section 4 identifies the mechanism responsible for SST anomalies creation. Then, oceanic and atmospheric feedbacks are determined in section 5 where simulations FR-OC and FR-AT are successively analyzed in sections 5.1 and 5.2. Last, results are summarized and discussed in section 6 .

\section{Model Description}

\subsection{Equations}

[11] The atmospheric part of the model is quasigeostrophic (QG) with global domain on the sphere and pressure as a vertical coordinate; it was developed by Marshall and Molteni [1993] (hereinafter referred to as MM93). A version of this model was used by Ferreira and Frankignoul [2001] and D'Andrea et al. [2005] for studies of the North Atlantic climate variability, while a more complex version was extended to the Southern Hemisphere by Haarsma et al. [2000]. The quasigeostrophic potential vorticity (PV) equation with dissipation and forcings:

$$
\frac{\partial q}{\partial t}=-J(\psi, q)-D_{q}(\psi)+\kappa F(\psi, T)+S_{q}
$$

is discretized at three vertical levels: 200,500 , and $800 \mathrm{hPa}$ (see Figure 1). Here $\psi$ is the QG stream function. $D_{q}$ represents linear dissipation terms including Ekman dis- 


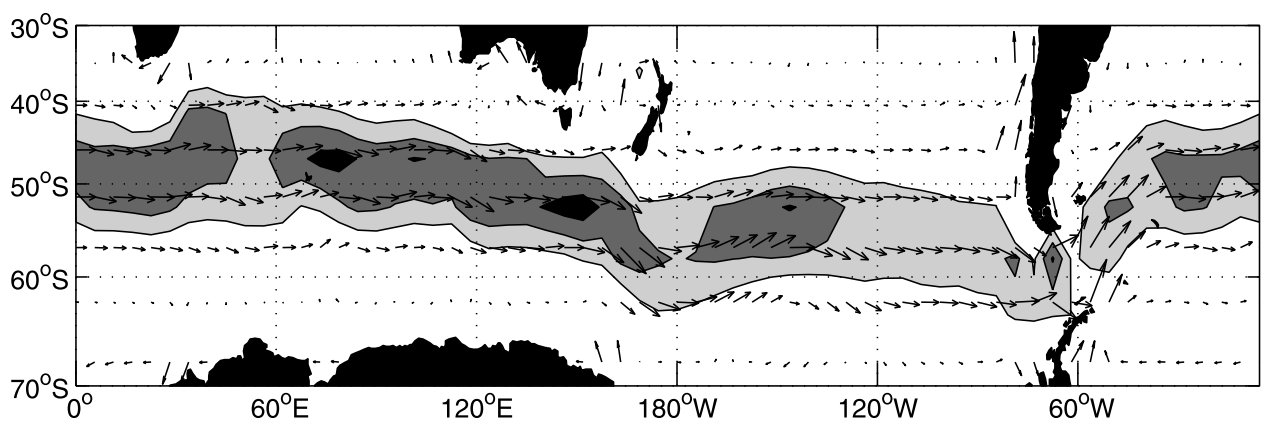

Figure 2. Absolute geostrophic surface current of the model. Light, medium, and heavy gray contours are for current's speed higher than 6,8 , and $10 \mathrm{~cm} \mathrm{~s}^{-1}$.

sipation (orography-dependent) and Newtonian thermal relaxation between the layers. Orographic effects are included in the PV definition at the lower level. $S_{q}$ is a time-independent source term added in order to give the model a realistic wintertime climatology. Winter was chosen as the season where coupling is strongest between the atmosphere and the ocean mixed layer. The forcing is computed empirically starting from the mean residual of equation (1) with respect to observations (see D'Andrea and Vautard [2000] and Appendix A for more details). The third term on the right-hand side of equation (1) is the forcing present at 500 and $800 \mathrm{hPa}$ (of equal amplitude but of opposite sign) due to heat exchange with the ocean. $F$ represents surface sensible and latent heat fluxes, given by the bulk aerodynamic formula

$$
F(\psi, T)=\rho_{a} C_{D} c_{p a}\left(1+B^{-1}\right)\left|\mathbf{U}_{\mathbf{s}}\right|\left(T-T_{s}\right)
$$

where $\rho_{a}$ is the dry air density, $C_{D}=1.3 \times 10^{-3}$ is a constant drag coefficient, $c_{p a}$ is the specific heat at constant volume for dry air, $B=0.5$ is the Bowen factor (ratio between sensible and latent heat fluxes), $\left|\mathbf{U}_{\mathbf{s}}\right|$ is the surface wind intensity, $T$ is the sea surface temperature, and $T_{S}$ is the surface atmospheric temperature. The expression of $\kappa$ is given by Ferreira and Frankignoul [2001] and D'Andrea et al. [2005]. Potential vorticity is the only atmospheric prognostic variable, surface variables $\mathbf{U}_{\mathbf{s}}$ and $T_{s}$ are consequently derived from it. $\mathrm{PV}$ insertion provides stream functions $\psi$ at 500 and $800 \mathrm{hPa}$. These in turn allow to diagnose the temperature at $650 \mathrm{hPa}$ (through thermal wind balance) and the $800 \mathrm{hPa}$ wind. A simple linear regression (coefficients were estimated from ECMWF analysis) finally provides surface variables $\mathbf{U}_{\mathbf{s}}, T_{s}$. Hence the dependence of $F$ on $\psi$ in equations (1)-(3). The ocean model is reduced to a single temperature equation for a mixed layer of constant depth $H_{o}$ with passive advection by constant geostrophic currents:

$$
\frac{\partial T}{\partial t}=-J\left(\psi_{g}, T\right)-\mathbf{U}_{\mathbf{E}} \cdot \nabla T-\frac{F(\psi, T)}{C_{p o}}-D_{T}(T)+S_{T}
$$

where $T$ is the SST, $C_{p o}=\rho_{o} c_{p o} H_{o}$ the heat capacity of the water column (with $\rho_{o}$ the water density and $c_{p o}$ the specific heat of seawater), $D_{T}$ a linear diffusion term and $S_{T}$ a source term computed in a similar way to the term $S_{q}$ in the PV equation. For more details about how this source term can be computed, see Ferreira and Frankignoul [2005] or D'Andrea et al. [2005]. $H_{o}$ can be very large in the SO and subject to a strong seasonal variability [Kara et al., 2003]. However, the average depth along the ACC's core, given $200 \mathrm{~m}$, was chosen for winter time conditions since $H_{o}$ is relatively uniform along this path, except upstream of Drake passage. Note that taking $H_{o}$ variable in space should only modify SST anomalies amplitude without altering the physical mechanisms we are interested in. The geostrophic advection by the ACC is introduced via a constant stream function $\psi_{g}$. It is obtained from the dynamic height relative to $1000 \mathrm{~m}$, the hydrology being that of Reynolds and Smith [1994]. A zonal transport of roughly $80 \mathrm{~Sv}$ was imposed at Drake passage (see http://www.mth.uea.ac.uk/ocean/ ALBATROSS/ for more details about this value). The associated geostrophic currents are shown at the surface in Figure 2. The mean zonal current between $40^{\circ} \mathrm{S}$ and $60^{\circ} \mathrm{S}$ is $6.7 \mathrm{~cm} \mathrm{~s}^{-1}$ and $8.3 \mathrm{~cm} \mathrm{~s}^{-1}$ along the ACC's core.

[12] The SST is dynamically forced by the atmosphere through two terms. Surface heat flux $F$ given in equation (2), and advection by Ekman currents, that are also given by bulk formulae:

$$
\mathbf{U}_{\mathbf{E}}=-\frac{\rho_{a} C_{D}\left|\mathbf{U}_{\mathbf{s}}\right|}{\rho_{o} f_{0} H_{o}} \mathbf{k} \times \mathbf{U}_{\mathbf{s}}
$$

where $f_{0}$ is the Coriolis factor at $45^{\circ} \mathrm{S}$ ( $\mathbf{k}$ is a vertical unit vector).

[13] The atmospheric (equation (1)) and ocean (equation (3)) models, coupled through (equation (2)) and (equation (4)), are integrated in time with a predictorcorrector scheme (first-order Adams-Bashforth-Mouton with a time step of 1 hour) and in space on the sphere with a triangular truncation to total wave number 21 (giving approximately a $5.6^{\circ} \times 5.6^{\circ}$ resolution for both the atmosphere and the ocean).

\subsection{Climatology of the CPL Simulation}

[14] Despite its simplicity the model has a fairly realistic climatology for both the atmosphere and the SO SST. As illustrated in Figure 3, mean $500 \mathrm{hPa}$ stream function is well reproduced as are the jet maxima in the western part of the Indian basin. Systematic departure of the geopotential from ECMWF June-July-Augsut (JJA) climatology (not shown) reaches a maximum of $248 \mathrm{~m}$ in the Pacific sector of the Antarctic continent but only $173 \mathrm{~m}$ at midlatitudes between $20^{\circ} \mathrm{S}$ and $64^{\circ} \mathrm{S}$. These values are comparable to those of many full fledged atmospheric global circulation models 

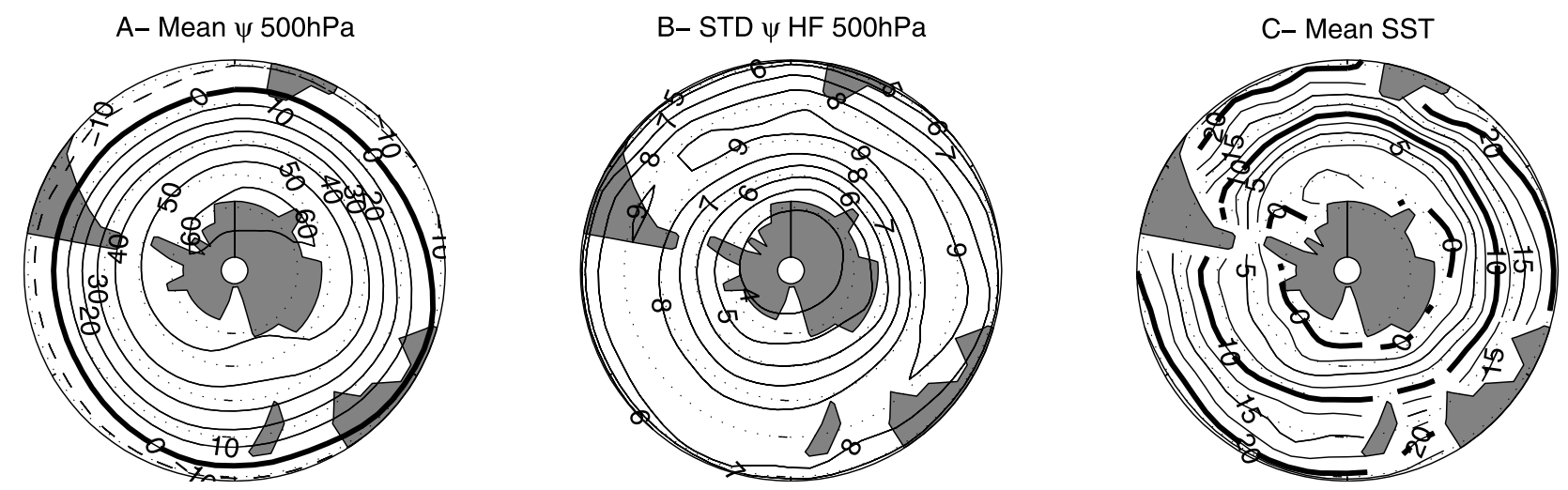

Figure 3. Climatological fields of the CPL simulation. (a) The $500 \mathrm{hPa}$ stream function long-term mean (contours every $10^{7} \mathrm{~m} \mathrm{~s}^{-2}$ ). (b) SD of $500 \mathrm{hPa}$ stream function fluctuations having period lower than 11 days (contours every $10^{6} \mathrm{~m} \mathrm{~s}^{-2}$ ). (c) SST long-term mean (contours every $2.5 \mathrm{~K}$ ).

(AGCMs) [D'Andrea et al., 1998]. Transient eddy activity, defined as the standard deviation (SD) of the $500 \mathrm{hPa}$ stream function high-frequency signal is characterized by a maximum of amplitude from eastern Atlantic to eastern Indian basins (Figure 3). The SD of geopotential reaches $100 \mathrm{~m}$ at $500 \mathrm{hPa}$ compared with $125 \mathrm{~m}$ in the observations.

[15] The long-term mean SST difference with respect to JJA climatological SST from Reynolds and Smith [1994] is less than $1 \mathrm{~K}$ all over the SO outside the limit of observed maximum sea ice extent (not shown). Also the strength of meridional gradient in the Indian Ocean, downstream of the Algulhas current is well represented (Figure 3).

\section{Southern Hemisphere Variability}

[16] The Southern Hemisphere interannual variability of the fully coupled integration CPL can be first described by the monthly standard deviation (SD) of SST (Figure 4). The variability is not uniform along a latitude circle with maximum value of $0.3 \mathrm{~K}$ occurring in the center of south Indian Ocean at $40^{\circ} \mathrm{S} / 73^{\circ} \mathrm{E}$. This differs from observations where the maximum is located in the Pacific Ocean [Cai and Baines, 2001; Park et al., 2004, hereinafter referred to as YP04].

[17] We use a Fourier method to decompose time/longitude signal into eastward/westward propagating and stationary components, see Appendix B for details [Park, 1990, YP04]. This decomposition method was preferred to others (such as complex empirical orthogonal function (EOF)) for its simplicity and to allow a direct quantitative comparison with YP04. Figure 5 shows the time resynthesized eastward propagating and stationary signal of monthly SST averaged between $41.5^{\circ} \mathrm{S}$ and $47^{\circ} \mathrm{S}$, for a 30 -year-long section of the integration. Different choices of latitude bands in the range $40^{\circ}-60^{\circ} \mathrm{S}$ have been tried, and no substantial change of results was found. Three main features can be observed.

[18] The stationary component is larger than the eastward propagating signal and the westward component (not shown) is negligible. The stationary and the eastward propagating signals account respectively for $51.2 \%$ and $37.7 \%$ of the total SD. Qualitatively, this is similar to what was found by YP04 in the Comprehensive OceanAtmosphere Data Set (COADS [Slutz et al., 1985]).
However, for the 25-year-long time series they analyzed, the stationary part accounts for $65 \%$ of the total while the eastward propagating part accounts $25 \%$.

[19] Note that while the amplitude of the eastward propagating component is zonally uniform, the amplitude of the standing signal is not, being maximum in the Indian basin. In YP04, the SST anomaly amplitude was maximum in the Pacific basin and associated to a stationary wave train remotely forced by ENSO.

[20] When looking at both standing and propagative signals, SST anomalies seem to appear in the Indian Ocean sector and then propagate eastward. A good example is given by the warm SST anomaly appearing around model year 212 at $60^{\circ} \mathrm{E}$ in the standing component panel. This anomaly can also be followed in the eastward component panel at the same time/longitude location and then traced for $8-10$ years before it disappears. A two-dimensional (2-D)

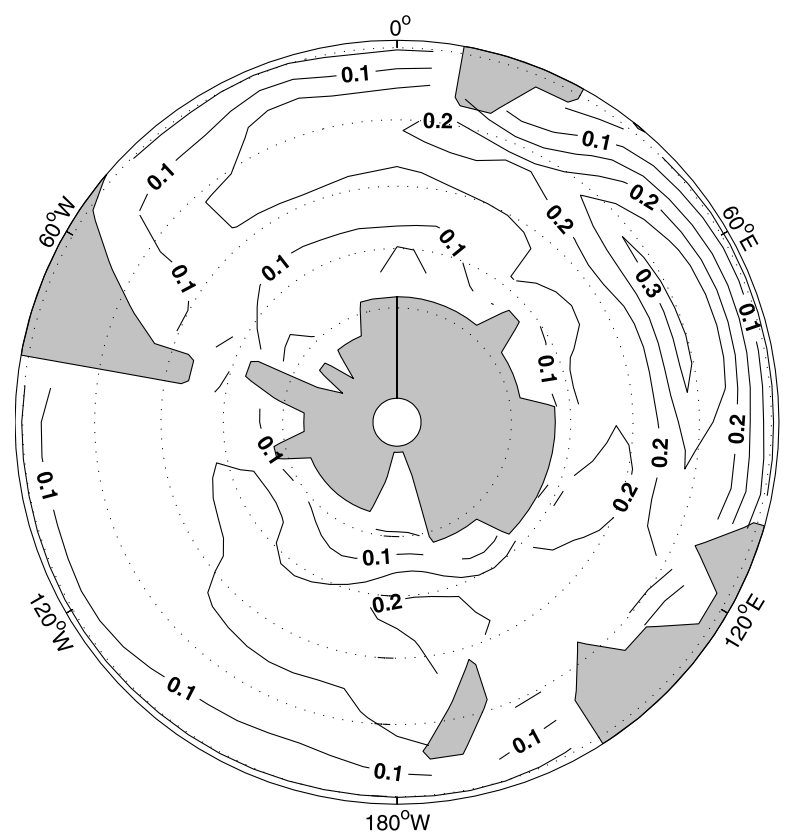

Figure 4. Standard deviation of monthly SST anomalies from the CPL simulation. Contours step $0.01 \mathrm{~K}$. 



Figure 5. (top) Hovmoller diagram of (a) total, (b) stationary, and (c) eastward components of SST anomalies from CPL simulation for a 30-year section of the integration. Anomalies have been averaged between $41^{\circ} \mathrm{S}$ and $47^{\circ} \mathrm{S}$ and band-pass filtered with a $2-20$ year band-pass filter. Contours every $0.05 \mathrm{~K}$, with zero contours thick, negative contours dashed, and positive contours shaded. (bottom) SD at each longitude for the entire simulation $(\mathrm{K})$.

power spectral density estimate (not shown) did not provide any significant frequency peaks for either signals (compare with Figure 9 in section 4). Propagation speed of SST was obtained objectively by using a method based on timelagged cross correlation between fixed and advected anomalies. Computing longitudinal autocorrelation of SST at a given time lag, the longitude of maximum correlation gives the longitudinal displacement of a SST anomaly in that time lag. Taking the mean over longitude and time, a displacement speed can be calculated. Error bars were estimated by subsampling the time series in five subsections. This yields a propagation speed of $40 \pm 5^{\circ} \mathrm{yr}^{-1}$. Since the averaged surface speed of the ACC is $8.3 \mathrm{~cm} \mathrm{~s}^{-1}$ (i.e., $35^{\circ} \mathrm{yr}^{-1}$ at $45^{\circ} \mathrm{S}$ and $44^{\circ} \mathrm{yr}^{-1}$ at $55^{\circ} \mathrm{S}$ ) the propagation of SST anomalies occurs at about the speed of the ACC.

[21] Geopotential height anomalies at $800 \mathrm{hPa}$ (hereafter Z800) also have a maximum in the Indian sector. The same 2-D Fourier decomposition was also performed on Z800 along a midlatitude circle. Stationary wave components dominate strongly over propagative ones as eastward and westward propagative components accounts for $21 \%$ of the total SD and the stationary component for $58 \%$.

[22] In order to illustrate how atmospheric variables are related to SST anomalies, we performed a composite analysis chained to SST anomalies. Eight points were selected along the ACC and composites chained to the SST time series at those points were obtained. Fields of SST, Z500, Z800, surface heat flux (SHF), Ekman heat flux
(EKF), and $U_{s}$, were averaged each time the SST series at the chosen location was higher than one SD. Except for the amplitude, no fundamental differences of pattern were found between the composites of a given variable at the different locations. Consequently, we show the average composite on the eight longitudinal locations, each map being recentered at the point selected for the SST scalar series. All maps, normalized to a $1 \mathrm{~K}$ amplitude of the SST, are shown in Figure 6.

[23] The composite SST anomaly is approximately $120^{\circ}$ wide in longitude and extends meridionaly up to $20^{\circ}$, forming a zonal wave number 1 pattern with an aspect ratio of $1 / 6$. The atmosphere is equivalent barotropic with positive geopotential height anomalies at the same longitude as the SST anomaly but shifted southward by $10^{\circ}$. There is however a slight westward vertical tilt of $10^{\circ}$ from bottom to top of atmospheric levels. As in baroclinic instabilities, such a tilt is the signature of horizontal anomalous heat advection. It has also been found in observations on monthly timescales [Kidson, 1999]. The meridional shift of high pressure induces an easterly wind anomaly $\left(-1 \mathrm{~m} \mathrm{~s}^{-1}\right)$ over the warm SST anomaly. Negative heat fluxes are found over warm SST anomaly $\left(-6 \mathrm{~W} \mathrm{~m}^{-2}\right)$, indicating a tendency to damp the SST. Easterlies blowing slightly northward of a positive SST anomaly normally induce poleward Ekman currents in the ocean mixed layer which create horizontal advection of warm water and hence positive Ekman induced heat fluxes with a maximum amplitude of $14 \mathrm{~W} \mathrm{~m}^{-2}$. In summary, the transient 

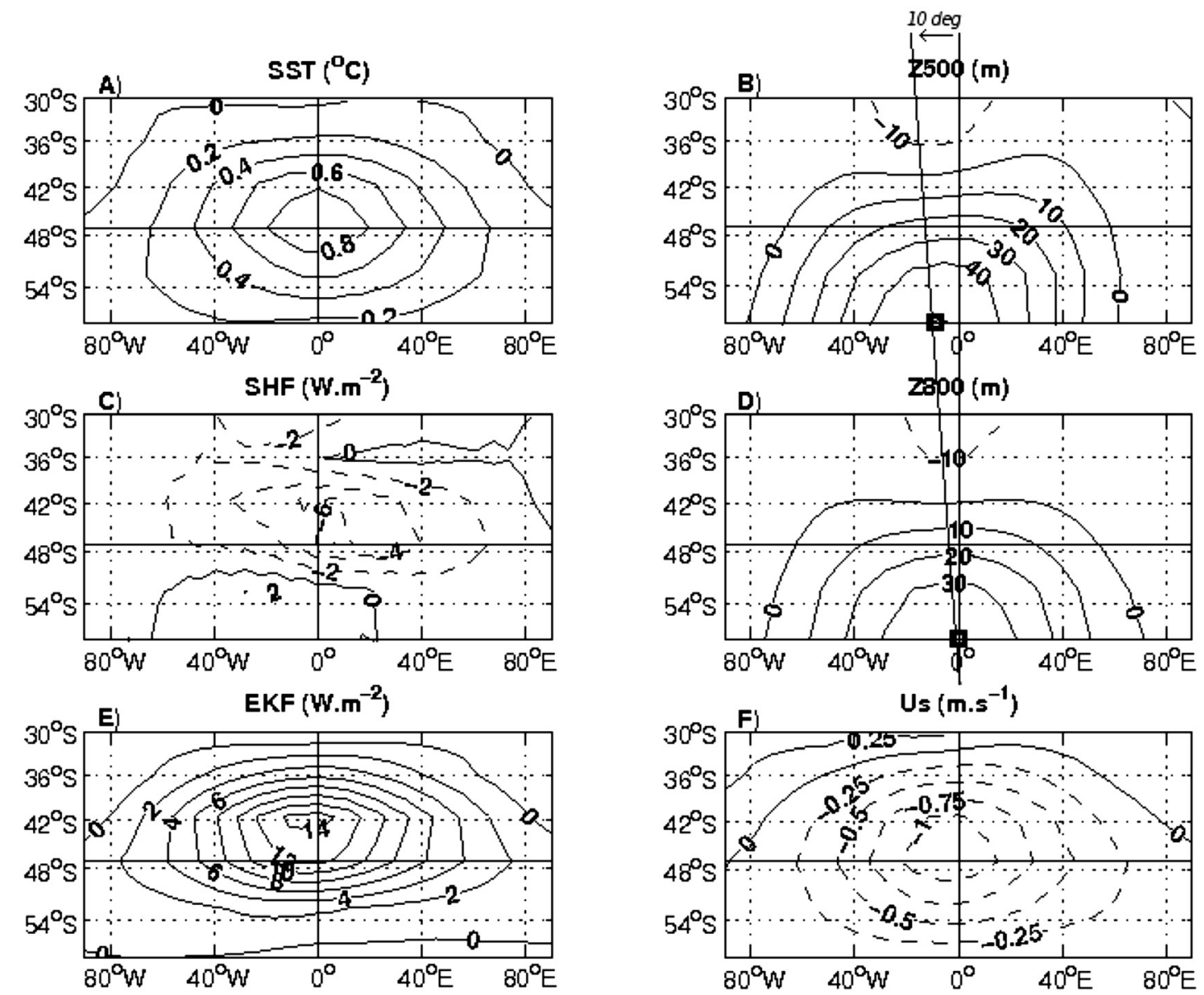

Figure 6. Normalized zonal mean composites associated to a 1 SD level SST anomaly centered at $47^{\circ} \mathrm{S}$. (a) SST, (b) geopotential height at $500 \mathrm{hPa}$, (c) SHF, (d) geopotential height at $800 \mathrm{hPa}$, (e) EKF, and (f) zonal surface wind. Heat fluxes are positive into the ocean. Negative contours dashed. Longitudes are relative to the SST anomaly center.

Ekman currents reinforce a SST anomaly while the surface heat flux tends to damp it.

\section{SST Anomalies Creation Mechanism}

[24] In order to understand how SST anomalies are created by the atmospheric forcing, it is necessary to describe how the components of the coupled system are connected to each other in space and time. The method used is the maximum covariance analysis (MCA) which identifies orthogonal patterns maximizing the covariance between two variables. It consists in the singular value decomposition (SVD) [Bretherton et al., 1992] of the cross-covariance matrix of the two fields. The method was applied to monthly anomalies, the anomalies have been area weighted but no time filtering has been applied.

[25] The dominant mode of covariability between SST and Z800 which accounts for $37.4 \%$ of the total covariance is shown in Figure 7. The atmospheric part has the signature of the Southern Annular Mode (SAM [Thompson and Wallace, 2000]) with low pressure centered over the Antarctic continent and extending to $55^{\circ} \mathrm{S}$ and pattern of opposite sign centered at $45^{\circ} \mathrm{S}$, extending zonally from the Atlantic to the western Pacific sector. The zero pressure contour occurs near latitude $60^{\circ} \mathrm{S} \pm 5^{\circ}$. This first mode is consistent with the observations in the Indian sector but observations exhibit a stronger pressure center in the western Pacific and western Atlantic.

[26] The oceanic counterpart of the first MCA mode is a dipolar SST anomalies with a minimum centered at $55^{\circ} \mathrm{S} /$ $120^{\circ} \mathrm{E}$ and a maximum at $40^{\circ} \mathrm{S} / 70^{\circ} \mathrm{E}$. The southern lobe extends all the way from the Indian to the western Pacific sector whereas the northern lobe extends from the eastern Atlantic to the Indian sector. The northern lobe is approximately 1.3 times stronger in amplitude than the southern one and is responsible for the maximum of SST variance described in section 3 . Both lobes are around $160^{\circ}$ wide, explaining the large extent of the SST composite shown in Figure 6. Note also how the high atmospheric pressure center appears to be in quadrature along a meridian with the dipole of SST anomalies.

[27] Time-lagged cross correlations between principal components (PC) of this first mode (Figure 8) indicate that Z800 leads SST by one month with a correlation value of 0.45 (statistically significant to $95 \%$ ). This very short timescale is consistent with the hypothesis of an ocean responding passively to the atmospheric forcing [Frankignoul and Hasselmann, 1977; Von Storch, 2000]. 

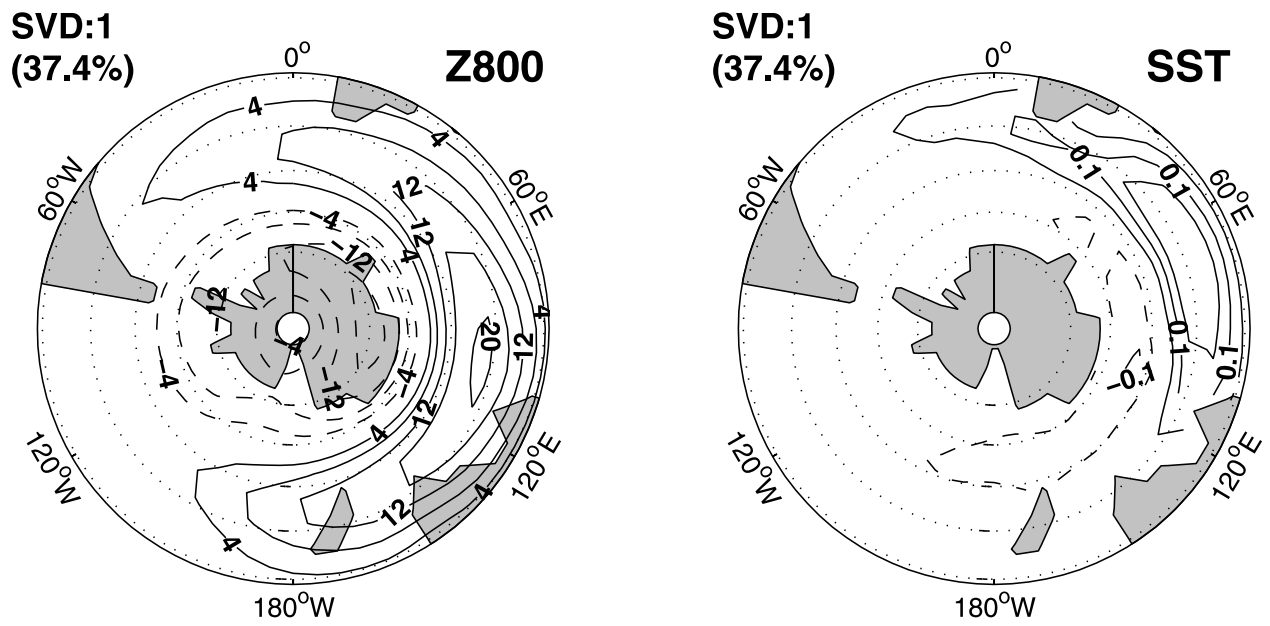

Figure 7. Leading MCA mode as regression of fields onto first principal component time series. (left) Z800 (m) and (right) SST (K). Contours are each $4 \mathrm{~m}$ for Z800 and $0.05 \mathrm{~K}$ for SST. Negative contours are dashed, and zero contour is omitted. The variance fractions of each modes are indicated. A Monte Carlo test has shown that they are statistically significant up to $99 \%$.

Moreover, as shown in Figure 9, spectral analysis of PCs reveals no significant peaks. The spectra of atmospheric variables PCs have a white noise shape with a slight increase of power at low frequencies whereas the spectrum of SST has a red noise shape. In agreement with [Visbeck and Hall, 2004], we found that the modelled Southern Annular Mode is the main mode of interannual variability in the Southern Hemisphere, without any preferred timescale.
[28] In order to identify how these oceanic and atmospheric patterns are linked, MCA analysis was also applied to surface heat flux (SHF) and Ekman heat flux (EKF).

[29] Figure 10 shows the first MCA mode of Z800 and EKF, accounting for $23.3 \%$ of the total covariance. The positive pressure anomaly centered at $45^{\circ} \mathrm{S}$ is covariant with positive EKF at $40^{\circ} \mathrm{S}$ and negative EKF at $50^{\circ}-55^{\circ} \mathrm{S}$ in the Indian Ocean (with maximum amplitude in the western and

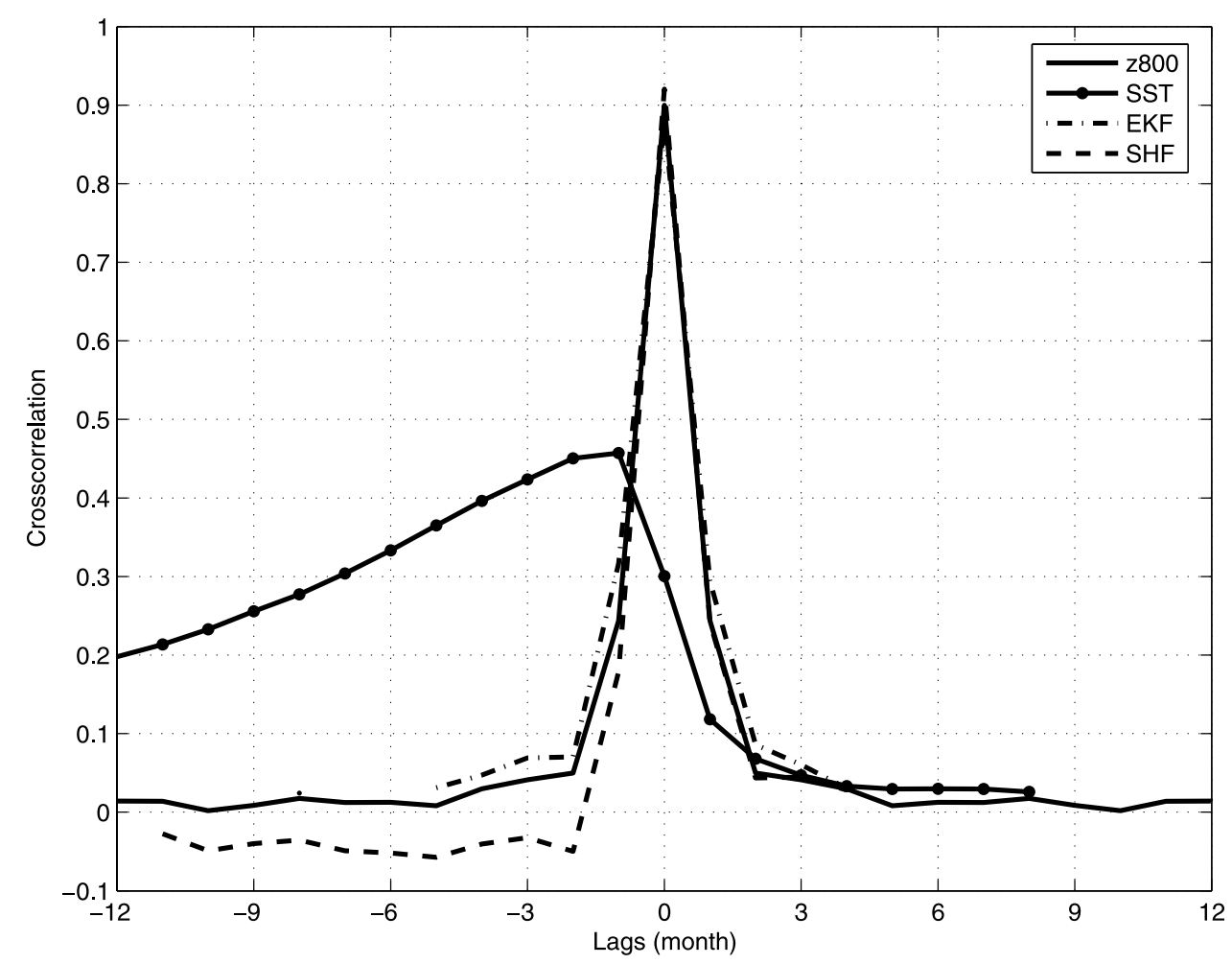

Figure 8. Time-lagged cross correlation between first PCs of SVDs between Z800 and SST, EKF, and SHF. Z800 leads on the right side and lags on the left side. Only correlations significant to 95\% are plotted. 

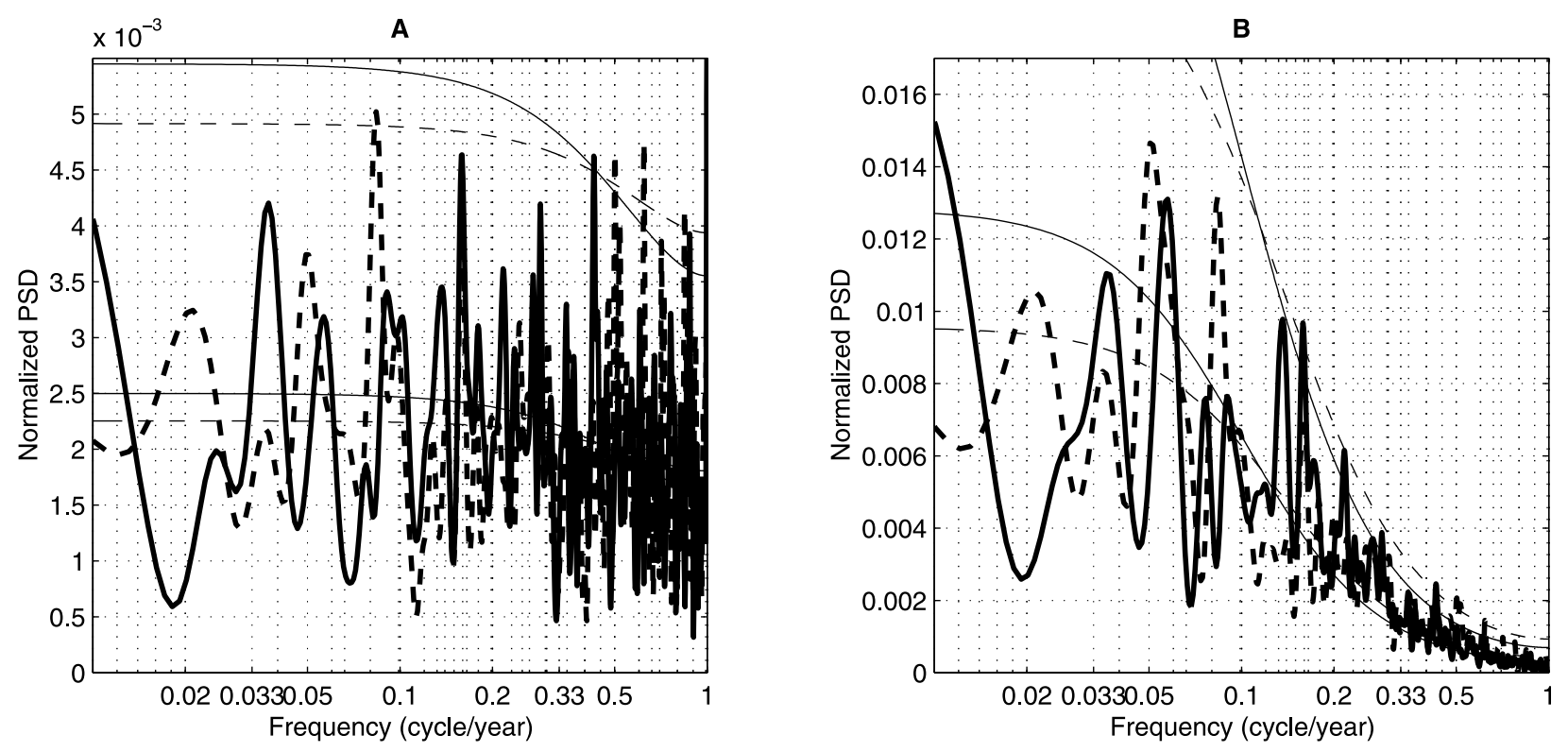

Figure 9. Normalized power spectral density (PSD) of PCs of first MCA mode for (a) Z800 and (b) SST (heavy lines) with a red noise fit (light lines) and 99\% confidence interval (light lines with vertical shift). In both plots, solid lines stand for the CPL experiments and dashed lines stand for the FR-OC experiment.

center sector). The first MCA mode of Z800 and SHF, accounts for $21.8 \%$ of the total covariance. The positive pressure anomaly is covariant with positive SHF at $35^{\circ} \mathrm{S}$ and negative at $55^{\circ} \mathrm{S}$ over the whole Indian Ocean. These positive (negative) heat fluxes are due to easterlies (westerlies) generated at $40^{\circ} \mathrm{S} / 35^{\circ} \mathrm{S}\left(50^{\circ} \mathrm{S} / 55^{\circ} \mathrm{S}\right)$ from the eastern Atlantic to the western Pacific by the high-pressure center. Zonal winds strongly enhance SHF amplitude and then in conjunction with the positive (negative) atmospheric temperature induced by the high-pressure center (not shown), produce the positive (negative) anomaly. Moreover these easterlies (westerlies) are associated with poleward (equatorward) Ekman currents at $40^{\circ} \mathrm{S}\left(55^{\circ} \mathrm{S}\right)$ which in turn have an influence in the western to center Indian Ocean where the meridional gradient of SST is high. As a result positive (negative) EKF develop.

[30] Figure 11 shows the first MCA mode of SST and EKF, accounting for $36 \%$ of the total covariance. The Indian basin intensified SST is covariant with EKF (once again with maximum in the western sector). The first MCA mode of SST and SHF accounts for $27 \%$ of the total covariance. The SST is globally in opposition of phase with SHF. More precisely, the maximum of SST is associated with a minima of SHF, whereas the eastern and western sides of the SST pattern are in phase with SHF.

[31] Although patterns of EKF are similar in Figures 10 and 11, patterns of SHF are different. This can be explained by looking at time lagged cross correlations between PCs of first SVDs mode (based upon Z800, Figure 8). Correlations between SHF/EKF and Z800 are in phase (maximum correlation occurs at time lag zero) and positive in the Z800 leading side (positive lags), indicating that the atmosphere drives heat fluxes in the way depicted in Figure 10. However, we can see on the Z800 lagging side (negative lags), that one month after the apparition of the SST anomaly (maximum correlation between SST and Z800 at time lag -1 month), Z800 and SHF become anticorrelated whereas Z800 and EKF are still positively correlated. This means that Z800 is driving positive SHF and EKF until a SST anomaly is created, then next, Z800 is still driving positive EKF, whereas SHF is now driven by the SST and becomes negative, as seen in Figure 11 [Von Storch, 2000]. Finally, positive SHF and EKF create warm SST anomaly in the CPL simulation, but with a leading role of EKF in sustaining the SST whereas SHF tends to damp it. Because of the main atmospheric pattern of variability (SAM) and it associated midlatitude high-pressure center, the SST anomalies creation mechanism is localized in the Indian Ocean. In such a process, the SO mixed layer variability seems to be passively forced by the atmosphere. The main question is now to determine the level of the ocean-atmosphere coupling role.

\section{Ocean-Atmosphere Coupling Role}

[32] The objective of this section is to identify how active is the coupling between the ocean and the atmosphere in establishing interannual variability in the CPL simulation. We analyze two simulations FR-OC and FR-AT where the ocean and the atmosphere are forced successively by the other.

\subsection{Forced Ocean}

[33] In the FR-OC simulation, the ocean is passively forced by the atmosphere which in turn only feel climatological boundary conditions at the ocean surface. A similar analysis as previously integration was performed on the FR-OC simulation. Results are qualitatively similar between the two simulations. However, some characteristics are different for SST and surface heat flux (SHF). Monthly anomalies of SST and SHF are now about $10 \%$ smaller in 

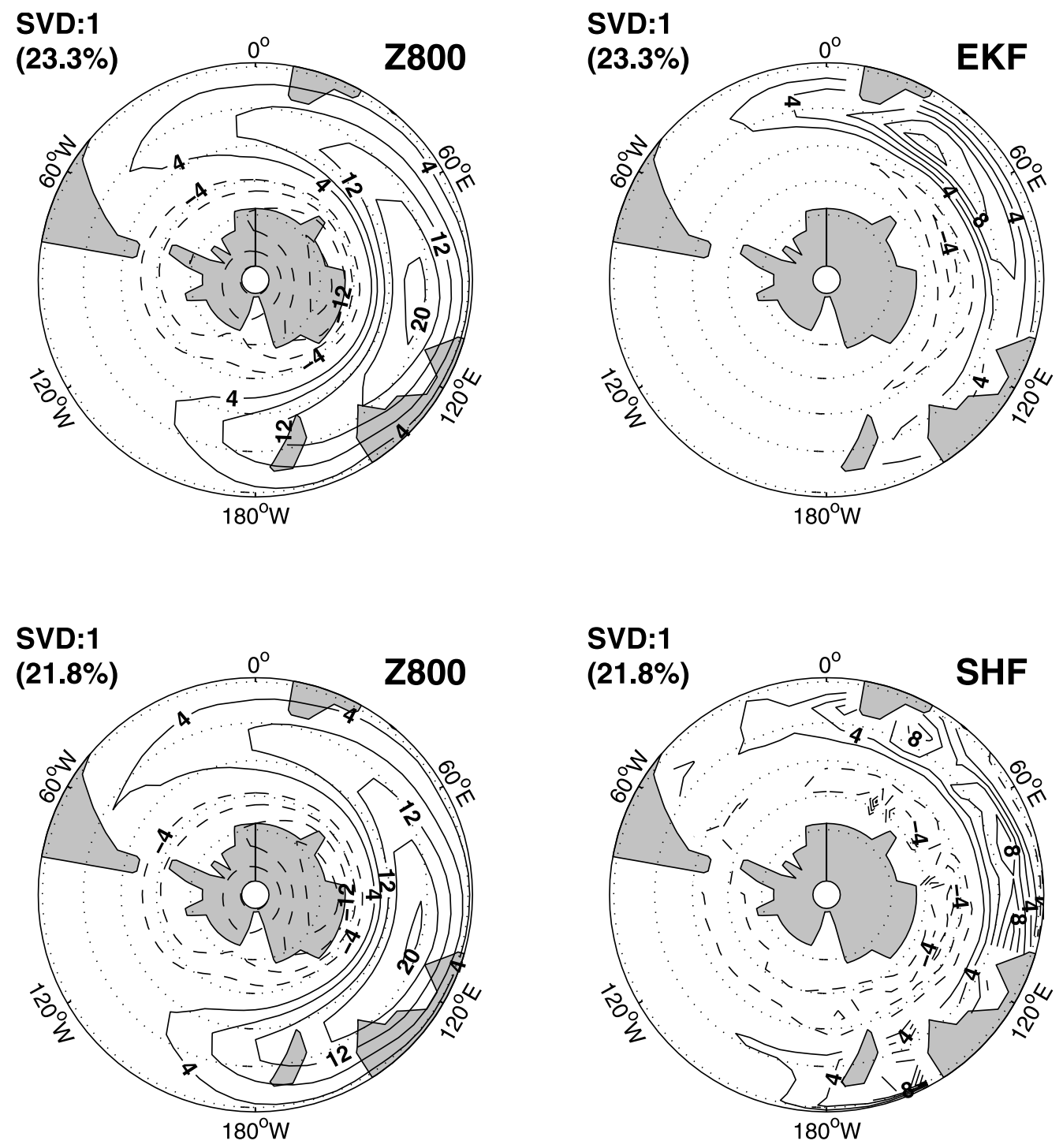

Figure 10. Leading MCA mode of the CPL simulation as regression of fields onto first principal component time series. (top) Between (left) Z800 (m) and (right) EKF (W m ${ }^{-2}$ ). (bottom) Between (left) $\mathrm{Z} 800(\mathrm{~m})$ and (right) SHF (W m ${ }^{-2}$ ). Contour step is $4 \mathrm{~m}$ for $\mathrm{Z} 800$ and $2 \mathrm{~W} \mathrm{~m}^{-2}$ for EKF and SHF, negative contour is dashed, and zero contour is omitted. The variance fractions of each mode are indicated on each plots. A Monte Carlo test has shown that they are statistically significant up to $99 \%$.

amplitude than in the CPL experiment. Moreover SST anomalies have longer lifetimes (e-folding time) in the CPL integration. These are estimated from the zonal mean time lagged autocorrelation function to be $8.9 \pm 0.3$ months for the CPL and $7.8 \pm 0.3$ months for the FR-OC integrations. These variations are small but significant due to the very long time series.

[34] In summary, SST anomalies are more persistent and of higher amplitude in the coupled simulation than in the forced one. Several mechanisms can be hypothesized to explain these differences. First, diminished SHF damping due to low-frequency equilibration of ocean and atmospheric temperatures, following Barsugli and Battisti [1998], could be a possibility since SHF anomalies are indeed $3 \mathrm{~W} \mathrm{~m}^{-2}$ weaker in the CPL integration than in the FR-OC one. This can be seen on PSDs of principal components of the first MCA mode shown in Figure 9, where the FR-OC experi- ment exhibits smaller variance at low-frequency (for timescale up to 2 years the cumulative variance is $7 \%$ higher in the CPL experiment). Second, there might be a positive dynamical feedback between the ocean and the atmosphere, this possibility is explored in section 5.2.

\subsection{Forced Atmosphere}

[35] In the FR-AT simulation the equilibrium atmospheric response to a prescribed SST anomaly is calculated and then the induced heat fluxes (that can feedback on the SST) are diagnosed. The SST anomaly pattern we choose to prescribe is the normalized composite computed in section 3 from the CPL simulation and shown in Figure 6a (top). The equilibrium atmospheric response to this SST anomaly is obtained as the 50-year long-term mean difference between the anomalous and control simulation performed with and without the added SST anomaly. 

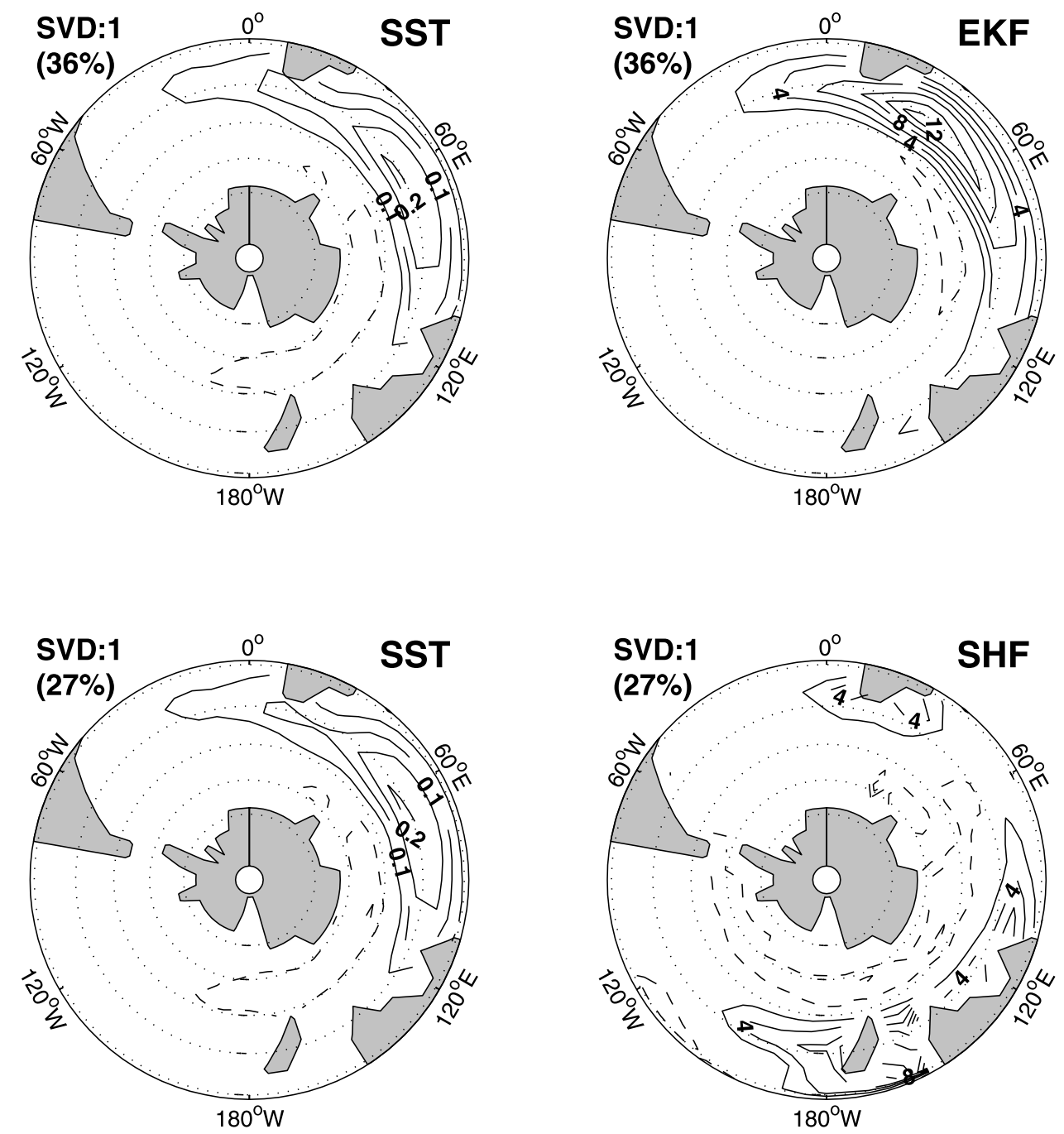

Figure 11. Leading MCA mode of the CPL simulation as regression of fields onto first principal component time series. (top) Between (left) SST (K) and (right) EKF (W m ${ }^{-2}$ ). (bottom) Between (left) SST $(\mathrm{K})$ and (right) SHF $\left(\mathrm{W} \mathrm{m}^{-2}\right)$. Contour step is $0.05 \mathrm{~K}$ for SST and $2 \mathrm{~W} \mathrm{~m}^{-2}$ for EKF and SHF, negative contour is dashed, and zero contour is omitted. The variance fractions of each mode are indicated on each plots. A Monte Carlo test has shown that they are statistically significant up to $99 \%$.

[36] Eight atmospheric responses to the SST anomaly composite centered at eight longitude along $47^{\circ} \mathrm{S}$ latitude have been computed. There is a small modulation of the response amplitude due to the position of the SST anomaly relatively to the storm track but detailed analysis of these responses will be the subject of future work. Here, we concentrate on the "average" response fields (defined as the average map on the eight longitudinal locations, each map being recentered at the point of SST anomaly maximum amplitude).

[37] The atmospheric response is summarized in Figure 12. It can be observed that the atmospheric pattern is meridionaly roughly in quadrature with the SST anomaly, i.e., high pressure southward and low pressure northward of the warm SST. Response at higher levels (500 and $200 \mathrm{hPa}$ ) show the same latitudinal position with an additional shift of about $30^{\circ}$ downstream (not shown). The response to negative SST anomalies are qualitatively similar but of opposite signs.

[38] In order to understand how this atmospheric pattern feedbacks on the ocean, EKF and SHF are diagnosed
(Figure 12). The pressure dipole over the SST induce anomalous easterly winds, which in turn produce poleward Ekman current and warm advection (positive EKF). EKF being globally positive with a maximum amplitude of $4 \mathrm{~W} \mathrm{~m}^{-2}$ provides a positive feedback on the SST. On the other hand SHF is negative all over the SST anomaly but with a much smaller amplitude than EKF, only $-0.6 \mathrm{~W} \mathrm{~m}^{-2}$.

[39] In summary there is evidence of a positive feedback through heat flux due to Ekman advection, and a much smaller negative one due to surface heat flux. In conjunction with the heat flux damping reduction mentioned above, these two mechanisms tend to reinforce SST anomalies in the coupled CPL integration.

\section{Discussion and Conclusion}

[40] Interannual variability of ocean-atmosphere coupled system was investigated in the Southern Ocean using an intermediate complexity model, that permits to isolate the purely extratropical part of the dynamics. The model includes 

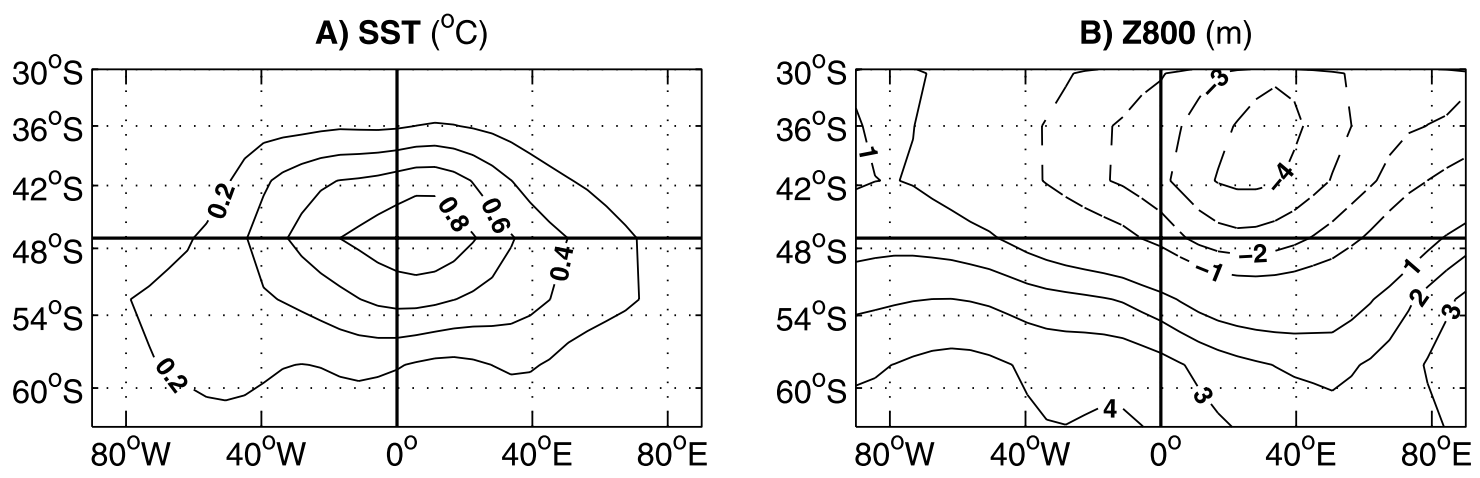

C) SHF $\left(W \cdot m^{-2}\right)$
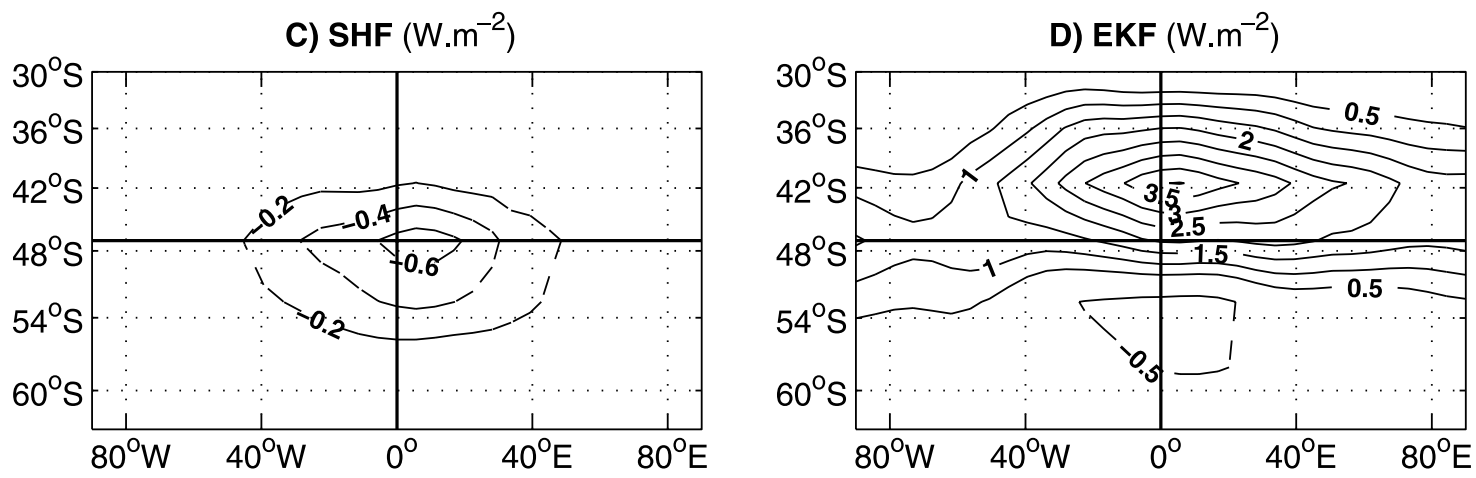

Figure 12. Atmospheric response to SST anomaly. (a) Composite SST anomaly pattern prescribed (contour step $0.2 \mathrm{~K}$ ). (b) Geopotential height response at $800 \mathrm{hPa}$ (contour step $1 \mathrm{~m}$ ). (c-d) Diagnosed SHF and EKF (contour step $0.2 \mathrm{~W} \mathrm{~m}^{-2}$ for SHF and $0.5 \mathrm{~W} \mathrm{~m}^{-2}$ for EKF). Fluxes are positive in the ocean. Negative contours are dashed, and zero contour is omitted. Longitudes are relative to the SST anomaly center, marked by horizontal and vertical black lines.

transient atmospheric eddies and an oceanic mixed layer with the mean geostrophic advection of the ACC; coupling occurs via heat fluxes (due to sensible and latent surface heat exchanges) and Ekman current advection of heat.

[41] The model has a realistic low-frequency variability. SST anomalies are produced by Ekman advection forced by the Southern Annular Mode variability, and are then advected along by the ACC. A forced mechanism where the sole role of the ocean is to advect the SST is sufficient to reproduce the main features of the variability. Nevertheless a positive feedback of the ocean on the atmosphere was identified which contributes to the maintenance of a SST anomaly through anomalous Ekman currents advection.

[42] Our model being purely extratropical, the principal mechanism of SST anomaly generation that we identified is the forcing by the SAM. This is demonstrated by the maximum covariance patterns of Figures 7-11. Like its northern counterpart, the SAM (also known as Antarctic Oscillation or AAO) is the principal mode of variability of the extratropical Southern Hemisphere at least up to interannual periods [Kidson, 1999]. At lower frequencies it is still under debate whether the SAM still is the principal mode of variability or whether this role would be taken over by propagative modes of zonal wave number 2 or 3 that form part of what is commonly called the ACW [Hall and Visbeck, 2002; White, 2004; Visbeck and Hall, 2004]. In our work, the SAM dominates the dynamics at all frequencies.

[43] That atmospheric forcing plus mean oceanic advection by the ACC is sufficient to explain the interannual
Southern Ocean variability patterns is in agreement with previous modeling studies like that of Weisse et al. [1999] and Haarsma et al. [2000], where advection by anomalous ocean current was shown to play no role in SST anomalies propagation. These studies proposed an advective resonance process similar that of Saravanan and McWilliams [1998] as the leading space/time selective mechanism explaining observed SST variability.

[44] This process was also found in the observational study by Verdy et al. [2006], a work of particular interest due to their use of an oceanic mixed layer model similar to ours. They forced it by National Center for Earthquake Prediction (NCEP) reanalysis data and found both the SAM and remote forcing by ENSO to be the main sources, and of equivalent importance, of SST variability along the ACC's core, and being in agreement with the advective resonance hypothesis. Because they separated the atmospheric forcing into the SAM and ENSO induced components of EKF and SHF, it is attractive to compare Verdy et al.'s [2006] results to ours. We found a similar SST anomalies amplitude for the Austral winter $(0.3 \mathrm{~K})$, a similar propagation speed $\left(8 \mathrm{~cm} \mathrm{~s}^{-1}\right)$ and also a predominant zonal wave number 1 pattern. However, they found EKF and SHF playing a equivalent role in sustaining and creating SST anomalies, which differs from our study where a predominance of the former upon the later was found. This discrepancy may be principally due to the fact that their ocean model cannot feedback on the atmosphere, which leads to an overestimated surface heat flux [Barsugli and Battisti, 1998]. Note also that their definition 
of the ACC's core localizes the 1-D ocean mixed layer model rather south compared to the high meridional SST gradient in the Indian Ocean, (see Verdy et al.'s Figure 9). This leads to underestimation of both EKF and SHF, but the underestimation is smaller for SHF. These two points are thought to be responsible for our slightly different conclusions about EKF versus SHF roles in the SO variability.

[45] Given the bias induced by limitations of the model physic (such as the absence of ENSO forcing and sea-ice influence that both move maximum of SST variability in the Pacific sector [Yuan and Martinson, 2000, 2001]), our model reproduces much of the interannual variability features that are found in observations. When decomposing the variability in a stationary and a propagative component, a dominance of the former against the latter was found as in YP04, even if the ratio stationary versus propagative components is smaller in our study. This may be due to the basic modeled ocean dynamic which does not alter the ACC geostrophic advection as much as in the reality.

[46] An important difference however is that the region of maximum SST variability found in our model is the Indian Ocean, linked to the SAM forcing, while observations (e.g., YP04 or Yuan and Martinson [2001]) place it in the Pacific sector, due to the forcing by ENSO. This is a critical point of our results; it emphasizes the role played by remote forcing from low latitudes in localizing a realistic SO interannual variability, as it was already noticed by Verdy et al. [2006]. Note that ENSO teleconnections may enhance the two-way coupling in the Southern Hemisphere midlatitudes ocean-atmosphere system and then make our study underestimate it compared to the reality. An investigations clearly separating low from mid-to-high atmospheric forcing of the SO variability needs to be conducted. Note also that in our study the SST creation location is simply driven by both the SAM geometry and the meridional SST gradient. A different SAM geometry, or other physical mechanisms such as a complete inner ocean dynamic or interactions with sea ice, may localize SST anomalies creation on the Pacific rather than in the Indian Ocean; see the low-resolution GCM study of Hall and Visbeck [2002].

[47] The time phase relations between oceanic and atmospheric anomalies (see Figure 8) are similar to those found by WP96 in the context of the Antarctic Circumpolar Wave studies. Some difference were nevertheless found. First, different lead lag times between oceanic and atmospheric variables were found; this is probably due to the severe time filter (3-7 years admittance) that they used while no time filter was applied to produce Figure 8.

[48] Second, our model exhibits somewhat different spatial phases relations between oceanic and atmospheric variables (see Figure 6) with respect to WP96 (and revised by Venegas [2003]). They observed high pressure downstream, i.e., eastward, of warm SST. Here, we find high pressure southward of warm SST. This is again due to preeminence of the Southern Annular Mode in the model's variability, which favors processes driven by zonal winds. Since temperature gradients (both in the ocean and in the atmosphere) are mainly meridional, two simple mechanisms are present. First, a high-pressure center induce meridional winds to advect warm/cold air and create a SST anomaly via SHF. This process leads to warm SST anomaly westward of high pressure. Second, a high-pressure center induces zonal winds and produce meridional Ekman currents which in turn advect warm/cold water and then create a SST anomaly via EKF. This process leads to warm SST anomaly northward of high pressure. White et al. [1998] revisited WP96 data analysis and found downstream high pressure to be also shifted southward to SST anomalies, forming a spiral pattern. This suggests that both processes described above occur in reality, producing a spiral pattern with high pressure east-southward of warm SST. Moreover, White et al. [1998] took a $f^{2}$ dependence of the atmospheric response to SST anomalies which allowed them to model analytically the spiral pattern. They found SST anomalies to be created and sustained by the ridge-induced poleward Ekman transport, as in our study. The importance of Ekman current heat advection in the coupled experiment CPL have been tested by performing two long coupled sensitivity integrations with a doubled constant drag coefficient, first only in the surface heat flux expression, and second only in the Ekman heat flux expression. If the SHF amplitude is increased, SST anomalies are smaller and shorter lived, which confirms the damping role of the turbulent surface heat flux. If on the other hand Ekman heat flux amplitude is increased, the opposite effect is observed.

[49] Spatial phase relations given by Figure 6 are very useful in attempt to compare our results to those from analytical models of ACW-like variability. Studies of Qiu and Jin [1997], Talley [1999], Goodman and Marshall [1999], and Baines and Cai [2000] are based on a positive feedback due to ocean dynamics in response to the overlying equilibrated atmosphere. Since the thermocline is mainly forced by the surface wind stress curl, a positive feedback needs a downstream or inphase high pressure at the same latitude than the SST anomaly. Given the absence of internal ocean dynamics in our coupled model, the mechanism for growth of the perturbations cannot have such an oceanic origin. On the other hand, the vertical phase lags of pressure patterns that we observe are consistent with an atmospheric energy source as found by Colin de Verdière and Blanc [2001] (hereinafter referred to as CB). Both Goodman and Marshall [1999] (hereinafter referred to as GM) and CB models produce equivalent barotropic response in the atmosphere at the scales for which Rossby waves are stationary (near resonance conditions) and we observe this equivalent barotropic response here, but it is more difficult to check if our dominant mode number one lies in the range of scales of stationary Rossby waves with realistic winds. The zonal phase shift between SST and SLP is absent by construction in GM while CB produces high SLP downstream of SST. The latter is consistent with the MCA results (Figure 7) but none of the two idealized models however, predict the meridional shift observed here. The main surface coupling flux in GM is EKF by construction (since their hypothesis of atmosphere equilibration requires SHF to be exactly zero) and EKF also plays the leading role here. On the other hand, SHF is the leading term (with a weaker contribution of EKF) which allows large growth rates in CB. Extending analytical coupled oscillations to more complex models seems to be difficult. This may be due to the presence of synoptic scale high-frequency activity which make harder to realize in a more complex geometry the parameters set allowing strong resonant conditions. 
[50] The relevance of the positive feedback mechanism of maintenance of the SST anomalies through EKF for real climate is difficult to estimate because it is critically dependent on the atmospheric response to SST anomaly, itself a highly studied process but still not completely understood in the extratropics [Kushnir et al., 2002]. A natural development to this work is consequently a more detailed study of atmospheric response to SST anomalies which will be the object of a forthcoming paper.

\section{Appendix A: PV Equation Source Terms}

[51] In the PV equation (1) we introduced a timeindependent source term $S_{q}$ that represents all adiabatic and subgrid processes [D'Andrea and Vautard, 2000]. This forcing is computed empirically as the mean residual of the equation with respect to observations following the method introduced by Marshall and Molteni [1993], to which we added a temperature correction. The PV equation (1) is satisfied by any choice of observed fields of $\hat{\psi}, \hat{q}$ and $\hat{T}$ (the hats indicate observations). Injecting a long observation data set into the PV equation and taking a long-term mean, the tendency on the left hand side goes to zero, and we obtain an equation for $S_{q}$ :

$$
S_{q}=[J(\hat{\psi}, \hat{q})]+[D(\hat{\psi})]-[\kappa F(\hat{\psi}, \hat{T})]
$$

The data used were twice daily ECMWF analysis data set ranging from June 1979 to August 1993 for June-JulyAugust, JJA. Brackets stand for the long-term mean.

[52] Using $S_{q}$ à la [Marshall and Molteni, 1993] in the case of the Southern Hemisphere gave a considerable high pressure error over the Antarctic continent. Consequently, we added a zonal mean temperature correction to term $S_{q}$. This term was computed in the following way.

[53] The Marshall and Molteni [1993] forcing (A1) can be interpreted as a relaxation temperature in the sense of Held and Suarez [1994]. Equation (1) can, in fact, be obtained eliminating the vertical velocity $\omega$ in the QG vorticity and temperature equations [cf. Holton, 1992, p. 164]:

$$
\begin{gathered}
\frac{d \nabla^{2} \psi}{d t}=f_{0} \frac{\partial \omega}{\partial p} \\
f_{0} \frac{d \psi}{d t}=-\sigma \omega+F(\psi, T)+\frac{R}{p} \frac{1}{\tau}\left(T^{*}-T\right)
\end{gathered}
$$

which gives

$$
\frac{D q}{D t}=\frac{f_{0}}{\sigma} \frac{\partial}{\partial p} F(\psi, T)-\frac{f_{0}}{\sigma} \frac{1}{\tau} \frac{\partial}{\partial p}\left[\frac{R}{p} T\right]+\frac{f_{0}}{\sigma} \frac{1}{\tau} \frac{\partial}{\partial p}\left[\frac{R}{p} T^{*}\right]
$$

Here, $q$ is the potential vorticity, $\psi$ the geostrophic stream function, $f_{0}$ the Coriolis factor at $45^{\circ}, \sigma$ the static stability, $R$ the gas constant and $\tau$ a relaxation timescale. The first term on the right-hand side of (A4) corresponds to the heat flux term in (1) and gives the expression of $\kappa$. The second term on the right-hand side of (A4) corresponds to the dissipation term of (1) with the dissipative relaxation time $\tau=25$ days.
Finally, the third term represents the Held and Suarez relaxation temperature.

[54] The Marshall and Molteni [1993] forcing method, in other terms, can be seen as an empirical way to compute a relaxation temperature $T^{*}$.

[55] In order to correct the forcing term $S_{q}$, we added a zonally uniform temperature $T^{*}$ and recomputed a new term $S_{q}^{\prime}$ :

$$
S_{q}^{\prime}=\frac{f_{0}}{\sigma} \frac{1}{\tau} \frac{\partial}{\partial p}\left[\frac{R}{p}\left(T^{*}+T^{\prime *}\right)\right]
$$

$T^{*}$ is pretty much an ad hoc term, it was computed as a fraction of the difference in meridional profile between $T^{*}$ and the observed meridional temperature profile.

\section{Appendix B: Two-Dimensional Fourier Decomposition}

[56] We can decompose a signal $\eta(x, t)$ as a sum of harmonics defined by the numbers $n$ and $m$ :

$$
\begin{aligned}
\eta(x, t)= & \sum_{n, m} A_{n m}^{w} \cos \left(k_{n} x+\omega_{m} t-\varphi_{n m}^{w}\right) \\
& +A_{n m}^{e} \cos \left(k_{n} x-\omega_{m} t-\varphi_{n m}^{e}\right)
\end{aligned}
$$

where $A_{n m}^{w}$ and $A_{n m}^{e}$ are the westward and eastward wave amplitudes, $k_{n}$ and $\omega_{m}$ are the spatial and temporal wave numbers, and $\varphi_{n m}^{w}$ and $\varphi_{n m}^{e}$ are the westward and eastward phase lags. All coefficients can be computed from Fourier transform. The reader is invited to see details in the works by Park [1990] and Park et al. [2004].

[57] Acknowledgments. Among the people that contributed to the article by discussion and exchange of ideas, the authors wish to thank Frédéric Vivier, Arnaud Czaja, David Ferreira, John Marshall, and Arianne Verdy. Thanks are also due to the ECMWF data center for making the ECMWF ERA-15 data freely available over the Web. We acknowledge support from CNES ("Southern Ocean Heat Storage Variability and Climatic Implications," NASA/CNES joint research announcement, the Ocean Surface Topography Science Team).

\section{References}

Baines, P. G., and W. Cai (2000), Analysis of an interactive instability mechanism for the Antarctic Circumpolar Wave, J. Clim., 13, 18311844

Barsugli, J. J., and D. S. Battisti (1998), The basic effects of atmosphereocean thermal coupling on midlatitude variability, J. Atmos. Sci., 55(4), 477-493.

Bonekamp, H., A. Sterl, and G. J. Komen (1999), Interannual variability in the Southern Ocean from an ocean model forced by European Center for Medium-range Weather Forecasts reanalysis fluxes, J. Geophys. Res., $104,13,317-13,331$.

Bretherton, C. S., C. Smith, and J. M. Wallace (1992), An intercomparison of methods for finding coupled patterns in climate data, J. Clim., 5, 541560

Cai, W., and P. G. Baines (2001), Forcing of the Antarctic Circumpolar Wave by ENSO teleconnections, J. Geophys. Res., 106, 9019-9038.

Cai, W., P. G. Baines, and H. B. Gordon (1999), Southern mid- to highlatitude variability, a zonal wavenumber-3 pattern, and the Antarctic Circumpolar Wave in the CSIRO coupled model, J. Clim., 12, 30873104.

Carril, A. F., and A. Navarra (2001), Low-frequency variability of the Antarctic Circumpolar Wave, Geophys. Res. Lett., 28, 4623-4626.

Christoph, M., T. Barnet, and E. Roeckner (1998), The Antarctic Circumpolar Wave in a coupled ocean-atmosphere GCM, J. Clim., 11, 16591672

Colin de Verdière, A., and M. Blanc (2001), Thermal resonance of the atmosphere to SST anomalies: Implications for the Antarctic Circumpolar Wave, Tellus, Ser. A, 53, 403-424. 
D'Andrea, F., and R. Vautard (2000), Reducing systematic errors by empirically correcting model errors, Tellus, Ser. A, 52, 21-41.

D’Andrea, F., et al. (1998), Northern Hemisphere atmospheric blocking as simulated by 15 general circulation models in the period 1979-1988, Clim. Dyn., 14, 385-407.

D'Andrea, F., A. Czaja, and J. Marshall (2005), Impact of anomalous ocean heat transport on the North Atlantic Oscillation, J. Clim., 18, 4955-4969.

Ferreira, D., and C. Frankignoul (2001), Coupled ocean-atmosphere dynamics in a simple midlatitude climate model, J. Clim., 14, 3704-3723.

Ferreira, D., and C. Frankignoul (2005), The transient atmospheric response to midlatitude SST anomalies, J. Clim., 18, 1049-1067.

Frankignoul, C., and K. Hasselmann (1977), Stochastic climate model. part II: Applications to sea-surface temperature anomalies and thermocline variability, Tellus, 29, 289-305

Goodman, J. C., and J. Marshall (1999), A model of decadal middlelatitude atmosphere-ocean coupled modes, J. Clim., 12, 621-641.

Haarsma, R., F. Selten, and J. Opsteegh (2000), On the mechanism of the Antarctic Circumpolar Wave, J. Clim., 13, 1461-1480.

Hall, A., and M. Visbeck (2002), Synchronous variability in the southern hemisphere atmosphere, sea ice, and ocean resulting from the annular mode, J. Clim., 15, 3043-3057.

Held, I., and M. Suarez (1994), A proposal for the intercomparison of the dynamical cores of atmospheric general circulation models, Bull. Am. Meteorol. Soc., 75, 1825-1830.

Holton, J. R. (1992), An Introduction to Dynamic Meteorology, Elsevier, New York.

Jacobs, G., and J. Mitchell (1996), Ocean circulation variations associated with the Antarctic Circumpolar Wave, Geophys. Res. Lett., 23, $2947-$ 2950.

Kara, A. B., P. A. Rochford, and H. E. Hurlburt (2003), Mixed layer depth variability over the global ocean, J. Geophys. Res., 108(C3), 3079, doi:10.1029/2000JC000736.

Kidson, J. W. (1999), Principal modes of Southern Hemisphere lowfrequency variability obtained from NCEP-NCAR reanalyses, J. Clim., $12,2808-2830$

Kushnir, Y., and I. M. Held (1996), Equilibrium atmospheric response to North Atlantic SST anomalies, J. Clim., 9, 1208-1220.

Kushnir, Y., W. A. Robinson, I. Bladé, N. M. J. Hall, S. Peng, and R. Sutton (2002), Atmospheric GCM response to extratropical SST anomalies Synthesis and evaluation, J. Clim., 15, 2233-2256.

Marshall, J., and F. Molteni (1993), Toward a dynamical understanding of planetary-scale flow regimes, J. Atmos. Sci., 50(12), 1792-1818.

Motoi, T., A. Kitoh, and H. Koide (1998), Antarctic Circumpolar Wave in a coupled ocean-atmosphere model, Ann. Glaciol., 27, 483-487.

Nakamura, H., G. Lin, and T. Yamagata (1997), Decadal climate variability in the North Pacific during the recent decades, Bull. Am. Meteorol. Soc., $78,2215-2225$.

Park, Y.-H. (1990), Mise en évidence d'ondes planétaires semi-annuelles baroclines au sud de l'océan Indien par altimétrie satellitaire, C.R. Acad. Sci., 310(2), 919-926.

Park, Y, F. Roquet, and F. Vivier (2004), Quasi-stationary ENSO wave signals versus the Antarctic Circumpolar Wave scenario, Geophys. Res. Lett., 31, L09315, doi:10.1029/2004GL019806.

Peterson, R. G., and W. B. White (1998), Slow oceanic teleconnections linking the Antarctic Circumpolar Wave with the tropical El NiñoSouthern Oscillation, J. Geophys. Res., 103, 24,573-24,583.

Qiu, B., and F.-F. Jin (1997), Antarctic circumpolar waves: An indication of ocean-atmosphere coupling in the extratropics, Geophys. Res. Lett., $24(21), 2585-2588$
Reynolds, R., and T. Smith (1994), Improved global sea surface temperature analyses using optimum interpolation, J. Clim., 7, 929-948.

Saravanan, R., and J. C. McWilliams (1998), Advective ocean-atmosphere interaction: An analytical stochastic model with implications for decadal variability, J. Clim., 11, 165-188.

Slutz, R., S. Lubker, J. Hiscox, S. Woodruff, R. Jenne, P. Steurer, and J. Elms (1985), Comprehensive Ocean-Atmosphere Data Set; Release 1, 268 pp., NOAA, Environ. Res. Lab., Boulder, Colo.

Talley, L. D. (1999), Simple coupled midlatitude climate models, J. Phys. Oceanogr., 29, 2016-2037.

Thompson, D. W., and J. M. Wallace (2000), Annular modes in the extratropical circulation. part I: Month-to-month variability, J. Clim., 13, $1000-1016$

Venegas, S. A. (2003), The Antarctic Circumpolar Wave: A combination of two signals?, J. Clim., 16, 2509-2525.

Verdy, A., J. Marshall, and A. Czaja (2006), Sea surface temperature variability along the path of the Antarctic Circumpolar Current, J. Clim., in press.

Visbeck, M., and A. Hall (2004), Reply to: Comments on 'Synchronous variability in the Southern Hemisphere atmosphere, sea ice, and ocean resulting from the annual mode', J. Clim., 17, 2255-2258.

Von Storch, J.-S. (2000), Signatures of air-sea interactions in a coupled atmosphere-ocean GCM, J. Clim., 13, 3361-3379.

Weisse, R., U. Mikolajewicz, A. Sterl, and S. Drijfhout (1999), Stochastically forced variability in the Antarctic Circumpolar current, J. Geophys. Res., 104, 11,049-11,064.

White, W. B. (2004), Comments on 'Synchronous variability in the Southern Hemisphere atmosphere, sea ice, and ocean resulting from the annual mode', J. Clim., 17, 2249-2254.

White, W. B., and J. Annis (2004), Influence of the Antarctic Circumpolar Wave on El Niño and its multidecadal changes from 1950 to 2001 , J. Geophys. Res., 109, C06019, doi:10.1029/2002JC001666.

White, W. B., and D. R. Cayan (2000), A global ENSO wave in surface temperature and pressure and its interdecadal modulation from 1900 to 1997, J. Geophys. Res., 105(C5), 11,223-11,242.

White, W. B., and R. G. Peterson (1996), An Antarctic Circumpolar Wave in surface pressure, wind, temperature and sea-ice extent, Nature, 380 , $699-702$.

White, W. B., S.-C. Chen, and R. G. Peterson (1998), The Antarctic Circumpolar Wave: A beta effect in ocean-atmosphere coupling over the Southern Ocean, J. Phys. Oceanogr., 28, 2345-2361.

White, W. B., S.-C. Chen, R. J. Allan, and R. C. Stone (2002), Positive feedbacks between the Antarctic Circumpolar Wave and the global El Niño-Southern Oscillation wave, J. Geophys. Res., 107(C10), 3165 doi:10.1029/2000JC000581

Yuan, X., and D. G. Martinson (2000), Antarctic sea ice extent variability and its global connectivity, J. Clim., 13, 1697-1717.

Yuan, X., and D. G. Martinson (2001), The Antarctic dipole and its predictability, Geophys. Res. Lett., 28(18), 3609-3612.

F. D’Andrea, Laboratoire de Météorologie Dynamique, 24, rue Lhomond, F-75231 Paris cedex 05, France.

A. Colin de Verdière and G. Maze, Laboratoire de Physique des Océans, Université de Bretagne Occidentale, UFR Sciences, 6, avenue Le Gorgeu C.S. 93837, F-29238 Brest cedex 3, France. (gmaze@univ-brest.fr) 